\title{
Fibroistiocitoma angiomatóide com metástase ao diagnóstico: relato de caso e revisão da literatura
}

\section{Angiomatoid fibrous histiocytoma presenting metastasis: case report and literature review}

Thaís Heinke'; Marcello Franco²; Maria Teresa de Seixas Alves³ Lucila Böhme Pellacani'; Ângela Navarro Gordan ${ }^{4}$; Antonio Sérgio Petrilli ${ }^{5}$

\begin{tabular}{l|l}
\multicolumn{1}{c|}{ Unitermos } & resumo \\
Fibroistiocitoma maligno & $\begin{array}{l}\text { O fibroistiocitoma maligno variante angiomatóide constitui entidade rara e geradora de controvérsia, } \\
\text { especialmente quanto a sua histogênese. Apresenta como peculiaridades o acometimento preferencial } \\
\text { angiomatóide }\end{array}$ \\
$\begin{array}{l}\text { Metástase } \\
\text { da faixa etária pediátrica e o comportamento biológico indolente, tendo baixas taxas de metastatização. } \\
\text { No presente caso, paciente feminina de } 6 \text { anos apresentou, em decorrência de lesão em extremidade } \\
\text { inferior, metástase linfonodal inguinal. }\end{array}$
\end{tabular}

\section{abstract key words}

Angiomatoid malignant fibrous histiocytoma is a rare and controversial entity, particularly as to its histogenesis. The tumor affects mostly the pediatric group, with an indolent clinical course and low rate of metastatization. In this report, the patient presented a lesion in the right foot and metastasis in an inguinal lymph node.

Angiomatoid malignant

fibrous histiocytoma

Metastasis

Cancer

\section{Introdução}

O fibroistiocitoma maligno variante angiomatóide (FHA) é entidade rara, constituindo desafio diagnóstico para muitos patologistas. Foi descrito por Enzinger, em 1979, em uma série de 41 casos, sendo considerado variante de sarcoma fibroistiocítico, com freqüência confundido clinicamente com hematoma, fato que retarda o diagnóstico precoce da lesão. Seu curso clínico, em geral, indolente, e a predileção pela faixa etária inferior à segunda década, diferenciam-no do fibroistiocitoma maligno convencional( ${ }^{(4)}$.
Devido à presença de pseudocápsula, infiltrado inflamatório linfoplasmocitário, freqüentes focos de hemorragia e proliferação de células fusiformes a redondas, o tumor tem sido incluído entre as lesões fibroistiocíticas ${ }^{(6)}$. O evento metástase é descrito na literatura mundial como raro, tendo freqüência estimada de $1 \%$ e, quando presente, constitui fator de pior prognóstico. Sua localização preferencial é em extremidades e tronco, havendo relatos de acometimento em regiões menos usuais, como mediastino ${ }^{(1)}$. A relação mulher/homem é

1. Médica-residente do Departamento de Patologia da Escola Paulista de Medicina da Universidade Federal de São Paulo (EPM/Unifesp).

2. Professor-titular do Departamento de Patologia da EPM/Unifesp.

3. Professora-adjunta do Departamento de Patologia da EPM/Unifesp.

4. Médica patologista, pós-graduanda do Departamento de Patologia da EPM/Unifesp.

5. Professor-adjunto do Departamento de Pediatria da EPM/Unifesp e diretor-geral do Instituto de Oncologia Pedíátrica.

Trabalho apresentado no XXIV Congresso Brasileiro de Patologia - Florianópolis, maio 2003. 
de 1:3(6). A taxa de recorrência é estimada em $12 \%$ e relaciona-se principalmente com margens irregulares de ressecção na peça cirúrgica e topografia de cabeça e pescoço(3).

\section{Relato do caso}

Paciente feminina, 6 anos, apresentou lesão dolorosa em dorso de pé simultânea a linfoadenomegalia inguinal ipsilateral, evoluindo com febre e adinamia.

Biópsia da lesão de membro inferior foi inicialmente diagnosticada como processo inflamatório crônico granulomatoso. As provas sorológicas e testes para agentes específicos (BAAR e fungos) foram negativas. Optou-se por exérese da lesão e dos linfonodos inguinais.

O material foi processado e analisado a partir da coloração de hematoxilina e eosina com posterior estudo imuno-histoquímico pelo método da estreptoavidina biotina-peroxidase para avaliar a positividade para actina de músculo liso (1A4), desmina, CD68, HHF35, AE1AE3 e proteína $\mathrm{S} 100$.

O exame microscópico da lesão primária em dorso de pé e de um dos três linfonodos dissecados revelou proliferação de células fusiformes ou redondas, atípicas, com núcleos volumosos e cromatina homogênea, e limites celulares evidentes. Na periferia das lesões, havia rima de infiltrado inflamatório linfoplasmocitário que, por vezes, permeava a neoplasia tanto na lesão primária (Figura 1) quanto na metástase linfonodal (Figura 2). O perfil imuno-histoquímico do tumor e da metástase demonstrou positividade para os marcadores CD68 e desmina (Figura 3 e Tabela). Ambas as biópsias foram enviadas em consulta ao Dr. Christopher Fletcher, da Harvard Medical School, Boston-USA, que confirmou o diagnóstico.

\section{Discussão}

O FHA constitui entidade controversa. Os fatores determinantes de seu comportamento biológico, sua epidemiologia e sua histogênese $\mathrm{e}^{(5)}$ vêm sendo estudados e relatados na literatura.

Estudos de biologia molecular aventam a possibilidade de fusão dos genes FUS e ATF1 em alguns destes tumores ${ }^{(8)}$.

O perfil imuno-histoquímico da neoplasia que revela positividade superior a $50 \%$ para desmina e eventual para marcadores musculares, associado ao fato de sítio primário freqüente em tecido linfóide, sugere sua origem em células mióides pré-existentes nessas regiões. No entanto, há ainda muita polêmica no que concerne à histogênese ${ }^{(6)}$.

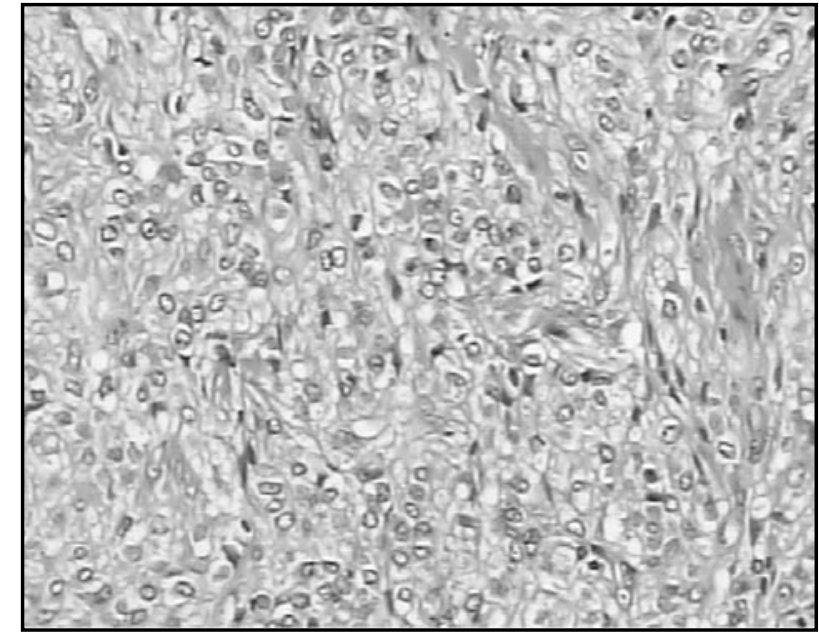

Figura 1 - Histopatologia da lesão primária no dorso do pé: proliferação de células fusiformes e histiociticas (HE, 40x)

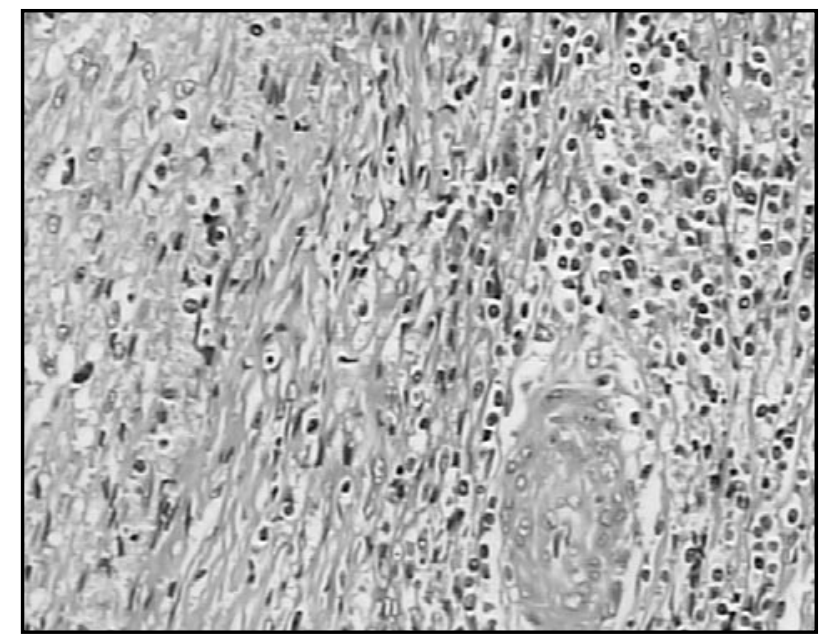

Figura 2 - Aspecto histológico da metástase em linfonodo inguinal (HE, 100x)

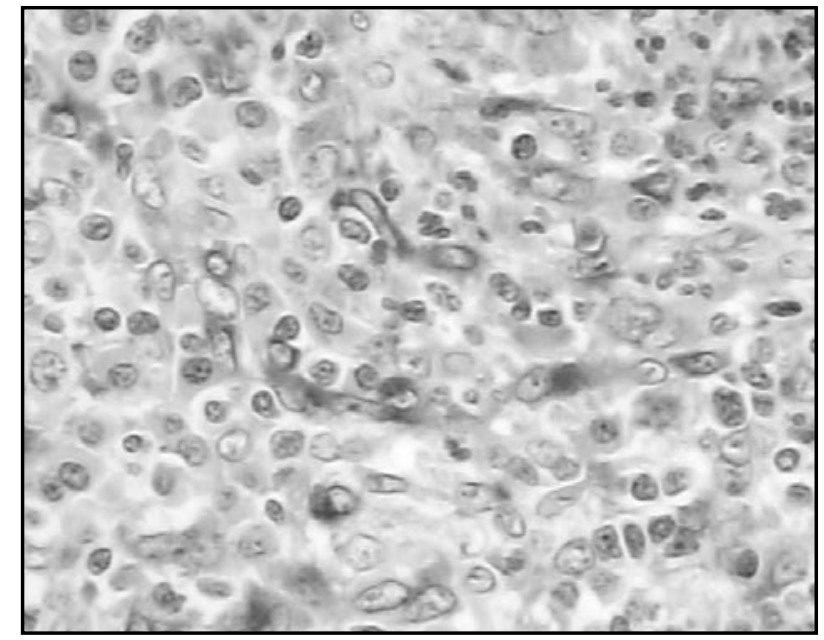

Figura 3 - Imunoexpressão de CD68 na lesão metastática em linfonodo $(I H, 100 x)$ 


\section{Perfil imuno-histoquímico do tumor}

Tabela e da metástase
CD68

Desmina

$1 \mathrm{~A} 4$

AE1AE3

HHF35
Positivo

Positivo

Negativo

Negativo

Negativo
No presente caso, houve metástase linfonodal, que constitui evento pouco freqüente. Enquanto a terapêutica para a lesão primária, independente do grau histológico do tumor, é a excisão cirúrgica ampla da lesão ${ }^{(7)}$, há relatos de tratamento quimioterápico adjuvante para lesões irressecáveis ou metastáticas, especialmente em pacientes adultos, com sucesso terapêutico(2)

Entre os diagnósticos diferenciais mais relevantes estão as variantes aneurismáticas de fibroistiocitomas benignos. Embora os espaços vasculares de FHA não sejam revestidos por endotélio, pode haver confusão em relação aos tumores vasculares, como o hemangioma epitelióide com rico componente inflamatório e outros tumores vasculares de acometimento cutâneo, como Sarcoma de Kaposi e hemangioendotelioma de células fusiformes. A imuno-histoquímica é de grande valia na diferenciação desses tumores (FHA é negativo para CD31, Fator VIIla e CD34). A positividade para desmina pode sugerir, especialmente pela idade jovem dos pacientes, rabdomiossarcoma. A ausente eosinofilia sugestiva de rabdomioblastos, a negatividade para marcadores musculares específicos e a lesão nitidamente circunscrita facilitam a exclusão desse diagnóstico.

Ainda, outros tumores mesenquimais primários de linfonodos, como o miofibroblastoma, podem mimetizar as lesões metastáticas do FHA. Porém, a ausência de atipias celulares significativas e a presença das fibras amiantóides, além de negatividade para desmina, colaboram na diferenciação(6).

A característica rima periférica de tecido linfóide desses tumores pode dificultar a diferenciação entre lesão primária e metástase em linfonodo; no presente caso, a metástase linfonodal poderia ter sido confundida com um outro foco tumoral, já que há relatos de lesões múltiplas de FHA na literatura ${ }^{(9)}$.

\section{Referências}

I. ASAKURA, S. et al. Angiomatoid fibrous histiocytoma of the mediastinum. Ann Thorac Surg, v. 72, p. 283-5, 2001.

2. BERNINI, J. C. et al. Adjuvant chemotherapy for treatment of unresectable and metastatic angiomatoid malignant fibrous histiocytoma. Cancer, v. 74, p. 962-4, 1994.

3. COSTA, M. J.; WEISS, S. W. Angiomatoid malignant fibrous histiocytoma.A follow-up study of 108 cases with evaluation of possible histologic predictors of outcome. Am J Surg Pathol, v. I4, p. I |26-32, 1990.

4. ENZINGER, F. M. Angiomatoid malignant fibrous histiocytoma. Cancer, v. 44, p. 2 147-57, 1979.

5. FAN, Q:;ALLEN, P.W.Angiomatoid malignant fibrous histiocytoma. Zhonghua Bing Li Xue Za Zhi, v. 25, p. 30-2, 1996.
6. FANBURG-SMITH, L. C.; MIETTINEN, M. Angiomatoid malignant fibrous histiocytoma: a clinicopathological study of 158 cases and further exploration of the myoid phenotype. Hum Pathol, v. 30, p. I336-43, 1999.

7. GROSSMAN, L. D.; WHITE, R. R.; ARBER, D. A. Angiomatoid malignant fibrous histiocytoma. Ann Plast Surg, v. 36, p. 649-5I, 1996.

8. RADDAOUI, E; DONNER, L. R.; PANAGOPOULOS, I. Fusion of the FUS and ATFI genes in a large deep-seated angiomatoid fibrous histiocytoma. Diagn Mol Pathol, v. I I, p. I57-62, 2002.

9. WOLF, H. K.; HARRELSON, J. M.; BOSSEN, E. H. Multicentric malignant fibrous histiocytoma of soft tissue. Am J Surg Pathol, v. 14, p. 188-93, 1990. 